\title{
Sistem Informasi Pengolahan Data Atlet Berbasis Web Pada Disporabudpar Tangerang
}

\author{
Padeli $^{1}$, Gustina ${ }^{2}$, Muhammad Fiqih Firmansyah ${ }^{3}$ \\ ${ }^{1}$ Program Studi Komputerisasi Akuntansi Universitas Raharja, \\ ${ }^{2}$ Program Studi Manajemen Informatika STTIKOM Insan Unggul Cilegon \\ ${ }^{3}$ Program Studi Sistem Informasi Universitas Raharja \\ E-mail: "11 padeli@ raharja.info, 22 gustina0881@gmail.com, \\ ${ }^{3}$ muhamadfiqihfirmansyah@ raharja.info
}

\begin{abstract}
Abstrak
Kebutuhan sistem informasi meliputi hampir semua bidang kehidupan. Informasi yang akurat, cepat, serta relevan sangat dibutuhkan dalam organisasi. Namun pada kenyataannya, karena kurang atau terbatasnya penggunaan sistem informasi terkadang tidak sinkron dengan keinginan serta harapan yang ingin diwujudkan. Disporabudpar Kabupaten Tangerang adalah organisasi yang perlu mengembangkan teknologi informasi yang dapat mengubah pengolahan datanya. Sistem pengolahan data atlet di Disporabudpar ini masih berupa file manual menggunakan dokumen dan data yang tersimpan masih dalam bentuk file Ms. Word dan Excel. Hal ini dapat memperlambat proses penginputan dan pengolahan data serta resiko kesalahan dan ketidakakuratan dalam penulisan yang dapat menyebabkan terjadinya proses pelaporan memakan banyak waktu. Metode analisa penelitian menggunakan Waterfall dan Unified Modeling Language (UML) sebagai metode perancangan berbasis bahasa pemrograman PHP dengan databasenya $M y S Q L$. Dikarenakan hal yang diatas maka diperlukannya sistem informasi pengolahan data atlet yang dibuat berbasis web untuk dapat diimplementasikan pada Disporabudpar Tangerang.
\end{abstract}

Kata Kunci : Rancang bangun, Sistem Informasi, Data Atlet, Web.

\begin{abstract}
Information system needs cover almost all areas of life. Accurate, fast, and relevant information is needed in organizations. But in reality, due to the lack or limited use of information systems, sometimes it is not in sync with the wishes and expectations that are to be realized. Disporabudpar Tangerang Regency is an organization that needs to develop information technology that can change its data processing. The athlete data processing system at Disporabudpar is still in the form of manual files using documents and the stored data is still in the form of Ms. Word and Excel. This can slow down the process of inputting and processing data as well as the risk of errors and inaccuracies in writing which can cause the reporting process to take a lot of time. The research analysis method uses Waterfall and Unified Modeling Language (UML) as a design method based on the PHP programming language with MySQL database. Due to the above, a web-based athlete data processing information system is needed to be implemented at the Tangerang Disporabudpar.
\end{abstract}

Keywords: Design, Information System, Athlete Data, Web.

\section{PENDAHULUAN}

Kebutuhan sistem informasi meliputi hampir semua bidang kehidupan. Informasi yang akurat, cepat, serta relevan sangat dibutuhkan dalam organisasi. Namun pada kenyataannya, karena kurang atau terbatasnya penggunaan sistem informasi terkadang tidak sinkron dengan keinginan serta harapan yang ingin diwujudkan. Dinas Olahraga pada Disporabudpar Kabupaten 
Tangerang adalah organisasi yang perlu mengembangkan teknologi informasi yang dapat mengubah pengolahan datanya. Sistem pengolahan data atlet di Sistem pengolahan data atlet di Disporabudpar ini masih berupa file manual menggunakan dokumen dan data yang tersimpan masih dalam bentuk file Ms. Word dan Excel. Hal ini dapat memperlambat proses penginputan dan pengolahan data serta resiko kesalahan dan ketidakakuratan dalam penulisan yang dapat menyebabkan terjadinya proses pelaporan memakan banyak waktu. Dalam upaya mengatasi permasalahan tersebut maka dibutuhkan rancang bangun mengenai sistem informasi yang menangani data-data atlet yang dibuat dengan berbasis web dan yang dapat diimplementasikan untuk Disporabudpar khusus wilayah Tangerang.

\section{TINJAUAN PUSTAKA}

\section{Perancangan Sistem}

Menurut Jimmi Hendrik P. Sitorus (2021), "Rancang bangun adalah step-step proses identifikasi kebutuhan dari siklus perkembangan sistem yang baru/sistem yang akan dibentuk." [1]

\section{Pengolahan Data}

Menurut Sutarman yang dikutip oleh Muhdar Abdurahman (2018), "Pengolahan data merupakan Counting Process atau bisa dikatakan sebagai Data Input Transformation yang membuat sebuah informasi menjadi mudah untuk dimengerti dan memiliki kesesuaian tujuan/dengan yang diinginkan”. [2]

\section{Atlet}

Menurut Sondakh yang dikutip oleh Indri Purwati (2019), “Atlet adalah pelaku olahraga yang di training dan terlatih dengan tujuan untuk diadu kekuatannya dengan lawan agar dapat meraih prestasi di tingkat daerah, tingkat nasional atau tingkat prestasi internasional”. [3]

\section{LITERATUR REVIEW}

1. Penelitian yang dilakukan oleh Karnadi dan Meilyana Winda Perdana (2020), yang berjudul "Aplikasi Pengolahan Data Atlet Berprestasi Pada KONI Kabupaten Pali Dengan Metode Waterfall". Berdasarkan perkembangan kebutuhan informasi pengolahan data atlet di lingkungan KONI Penukal Abab Kabupaten Lematang Ilir maka dibahas pembangunan sistem baru yang dapat mengolah data secara cepat dan akurat serta dapat diupdate secara cepat (terbaru). Kelebihan pengolahan data atlet secara komputerisasi adalah data yang disimpan memiliki ukuran dan lokasi yang praktis, misalnya dapat disimpan dalam memori flash sehingga dapat mempermudah proses pencarian data atlet dan menyalinnya sebanyak mungkin [4]

2. Penelitian yang dilakukan oleh Mochamad Yusuf Romdoni dan Irma Yunita Ruhiawati (2020), yang berjudul "Sistem Informasi Data Atlet Pada KONI Provinsi Banten". Dalam penelitian ini membahas mengenai sistem yang dirancang untuk membantu memproses data atlet dari berbagai kategori, dan kemudian menggunakannya sebagai saran bagi atlet yang bersiap untuk berpartisipasi dalam kompetisi.. Sistem informasi data atlet dibangun atas dasar pengolahan data atlet pembantu.Agar pengolahan data atlet lebih efektif dan cepat, sistem mengadopsi perancangan metode pengembangan waterfall, dan perancangan alur program mengadopsi flowchart untuk menjadi lebih jelas bagaimana sistem informasi atlet beroperasi sesuai dengan mekanisme pengolahan data yang baik untuk input, pengolahan dan output menjadi lebih jelas. Bahasa pemrograman yang digunakan merupakan bahasa visual basic yang sudah populer dan sudah terbukti kemampuannya dalam menangani mengolah data, yang dalam hal ini databasenya adalah $M y S Q L$. Sistem informasi ini 
tentunya bukan tanpa kelemahan, dan diharapkan kedepannya akan terus dikembangkan agar dapat terus bermanfaat dan mudah dioperasikan. [5]

3. Penelitian yang dilakukan oleh Dita Ferdian Bayu Kusuma dkk (2021), yang berjudul "Design and Build a Website-Based IKASI Athlete Data Processing Application Using the Laravel Framework". Penelitian ini berfokus pada : Making a website-based IKASI athlete data processing application is the goal of this research. This study describes the creation of data processing applications and monitoring of athlete development. Designed using the Waterfall method, where the manufacturing process is carried out in stages until testing is carried out. The results of this study show that $84.76 \%$ of users say that this application agrees to monitor the progress of athletes to make it easier in every exercise and competition. [6]

\section{METODE PENELITIAN}

\subsection{Metode Pengumpulan Data}

Penelitian ini menggunakan metode pengumpulan data antara lain :

a. Observasi

Melakukan direct observation di lokasi penelitian yaitu pada dinas Disporabudpar wilayah Tangerang untuk mendapatkan informasi yang lengkap dan yang dibutuhkan dalam penelitian ini.

b. Wawancara

Melakukan wawancara untuk memperoleh informasi langsung dari Stakeholder yaitu Bapak Mujiyanto, S.Pd., M.Si tentang pengolahan data atlet yang berkaitan dengan penelitian ini.

c. Studi Pustaka

Mencari data yang lengkap dengan mencari artikel, media internet dan juga jurnal sebagai bahan referensi yang terkait dengan sistem pengolahan data atlet ini.

\subsection{Metode Analisa Sistem}

Metode Analisa Sistem pada penelitian ini menggunakan metode analisa Air Terjun/Waterfall yang terdiri dari 5 (lima) hal dibawah ini :

\section{Requirement Analysis and Definition}

Tahapan untuk menganalisa kebutuhan User yang analisa kebutuhannya dilakukan kepada pihak yang menangani bidang Bidang Olahraga pada Disporabudpar wilayah Tangerang dengan melakukan diskusi langsung yang kemudian informasinya dianalisa agar mendapatkan data untuk membuat sistem informasi pengolahan data atlet yang dibutuhkan.

\section{System and Software Design}

Rancangan sistem dan perangkat lunak dibuat sebagai draft/gambaran tampilan sistem informasi pengolahan data atlet yang ingin dibuat dan disesuaikan dengan tujuan, yang penggambaran sistemnya dapat dilihat dari berbagai diagram UML seperti Use case diagram, Sequence diagram, Activity Diagram dan Class Diagram.

\section{Implementation}

Implementasi diperlukan agar sistem informasi pengolahan data atlet yang dibuat berbasis Web ini dapat diterima, diterapkan dan digunakan oleh User/Stakeholder yang ada pada Disporabudpar Tangerang ini. Sistem Informasi pengolahan data atlet ini 
dibuat berbasis Web dengan bahasa pemrograman PHP, dengan framework CI (Code Igniter) serta basis data MySQL.

\section{Integration and Testing}

Integration dan Testing merupakan tahap penggabungan dan pengujian perangkat lunak yang berbasis Web untuk dapat mengolah data atlet yang harus diuji oleh Customer sebelum digunakan untuk diketahui kelebihan dan kekurangannya.

\section{Operation and Maintenance}

Operation dan Maintenance merupakan tahap setelah sistem informasi pengolahan data atlet ini selesai dibuat, kemudian digunakan/diimplementasikan oleh User dan setelahnya dilakukan perawatan dan pemeliharaan Web yang telah dibuat dan digunakan ini.

\subsection{Metode Perancangan Sistem}

Metode perancangan sistem untuk sistem informasi pengolahan data atlet berbasis web ini digambarkan analisanya menggunakan diagram-diagram yang ada pada UML, bahasa pemrogramannya menggunakan PHP, basis datanya $M y S Q L$, desain dan tampilan dengan Sublime Text, servernya XAMPP sebagai penghubung bahasa pemrograman.

\subsection{Metode Pengujian Sistem}

Metode pengujiannya menggunakan Pengujian Kotak Hitan/Black Box Testing yang memfokuskan pada fungsional software yang ada.

a. Login Aplikasi

Tabel 1. Login Aplikasi

\begin{tabular}{|c|c|c|c|c|c|}
\hline No & $\begin{array}{c}\text { Skenario } \\
\text { Pengujian }\end{array}$ & Test Case & $\begin{array}{l}\text { Hasil Yang } \\
\text { Diharapkan }\end{array}$ & $\begin{array}{c}\text { Hasil } \\
\text { Pengujian }\end{array}$ & Keterangan \\
\hline 1 & $\begin{array}{l}\text { Mengosongkan } \\
\text { semua kolom } \\
\text { username dan } \\
\text { password }\end{array}$ & $\begin{array}{l}{ }_{\text {DISPORA }} \\
\vdots \\
\end{array}$ & $\begin{array}{l}\text { Sistem akan } \\
\text { menolak dan } \\
\text { tidak akan } \\
\text { dapat login }\end{array}$ & 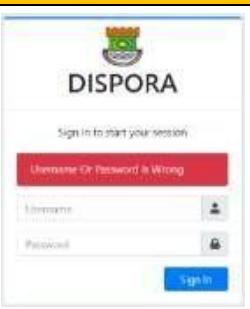 & Valid \\
\hline 2 & $\begin{array}{l}\text { Apabila salah } \\
\text { memasukkan } \\
\text { username dan } \\
\text { password }\end{array}$ & 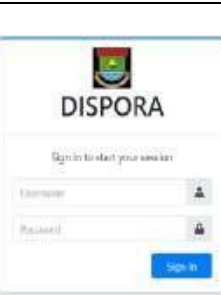 & $\begin{array}{l}\text { Sistem akan } \\
\text { menolak dan } \\
\text { menampilkan } \\
\text { pesan gagal }\end{array}$ & $\begin{array}{c}\text { DISPORA } \\
\vdots \\
\vdots \\
\end{array}$ & Valid \\
\hline 3 & $\begin{array}{l}\text { Apabila } \\
\text { username dan } \\
\text { password } \\
\text { benar }\end{array}$ & 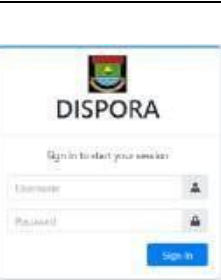 & $\begin{array}{l}\text { Sistem } \\
\text { berhasil login } \\
\text { dan masuk } \\
\text { kedalam } \\
\text { dashboard }\end{array}$ & $\left.\right|_{-\infty} ^{0}$ & Valid \\
\hline
\end{tabular}


2. Testing Aplikasi

Tabel 2. Testing Aplikasi

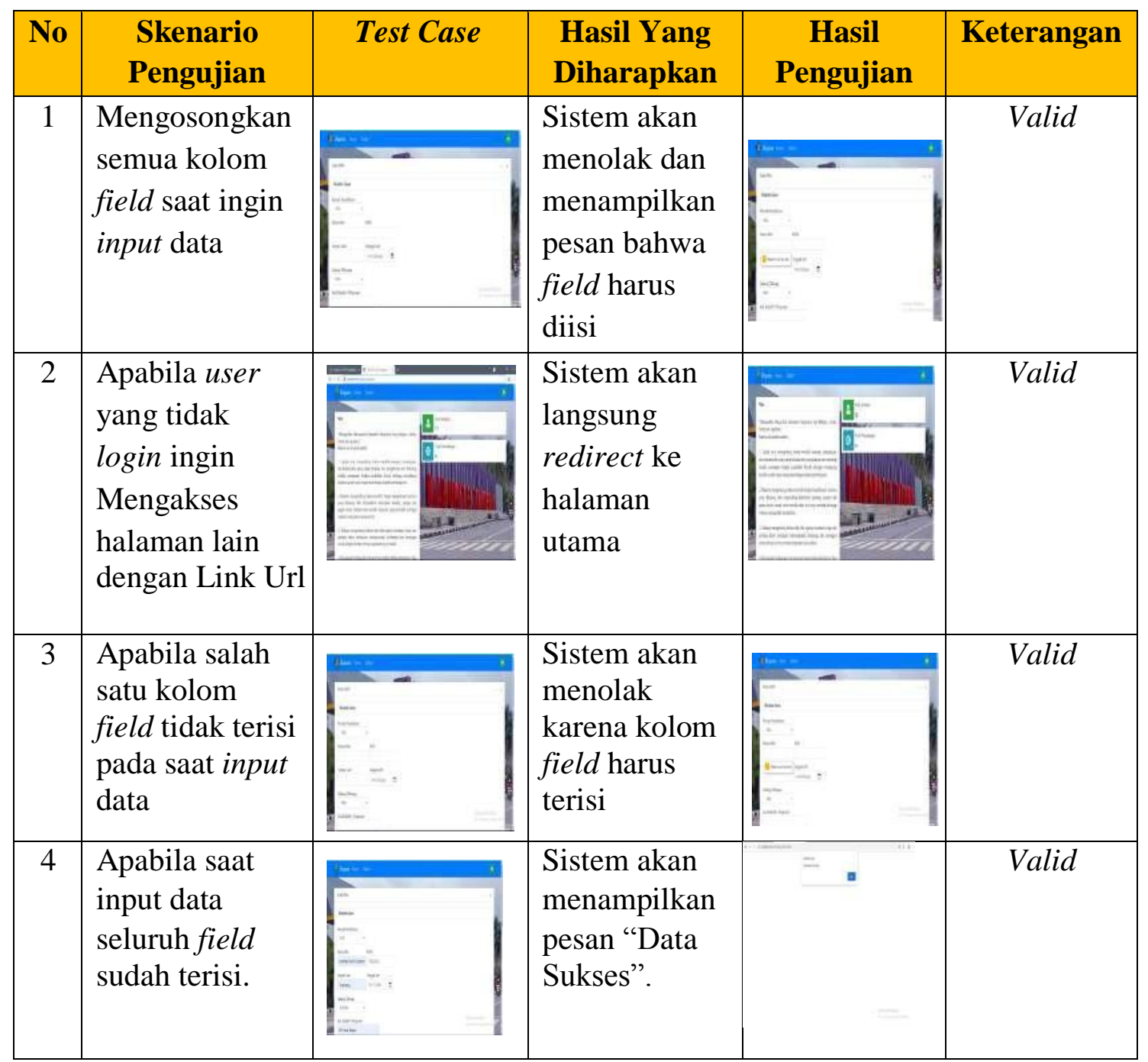

\section{PEMBAHASAN}

Pembahasan ini menjabarkan tentang penggambaran sistem penelitian ini dengan menggunakan diagram-diagram UML yang telah digambarkan seperti dibawah ini :

\subsection{Use Case Diagram Sistem yang diusulkan}




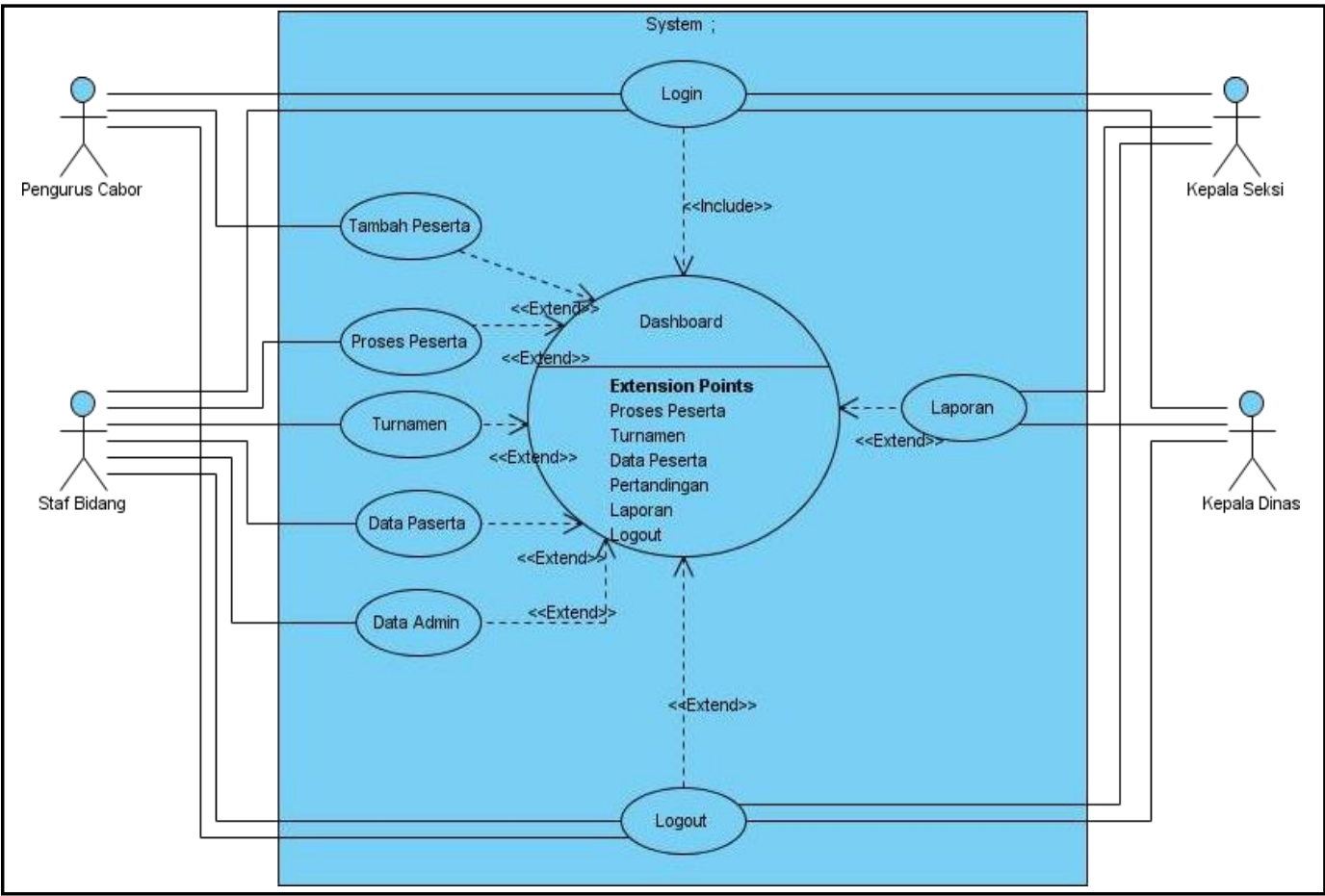

Gambar 1. Use Case Diagram yang diusulkan

\subsection{Activity Diagram Sistem yang diusulkan}

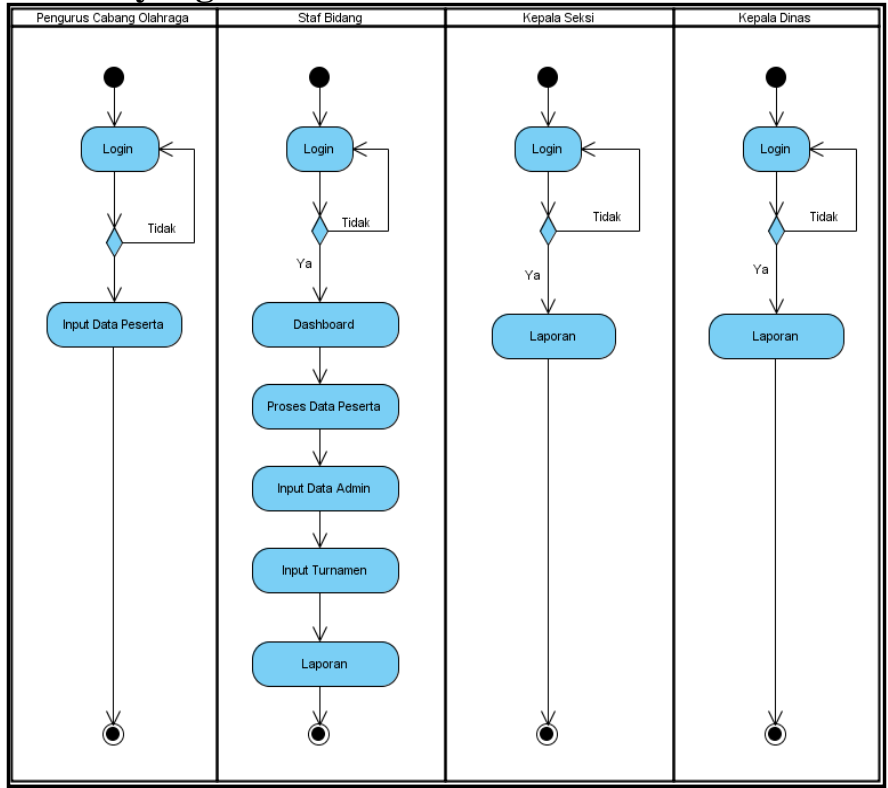

Gambar 2. Activity Diagram Sistem yang diusulkan

Pada Activity diagram sistem yang diusulkan, terdapat :

1. Terdapat 4 (empat) Initial Node untuk mengawali sistem.

2. Terdapat 12 (dua belas) Action State dari sistem yang mencerminkan eksekusi dari suatu aksi pada sistem yang diusulkan.

3. Terdapat 4 (empat) Decision Node, apabila login berhasil maka akan masuk ke menu dashboard, jika tidak berhasil akan kembali ke menu login.

4. Terdapat 4 (empat) Final Node, sebagai objek yang diakhiri. 


\subsection{Sequence Diagram Sistem yang diusulkan}

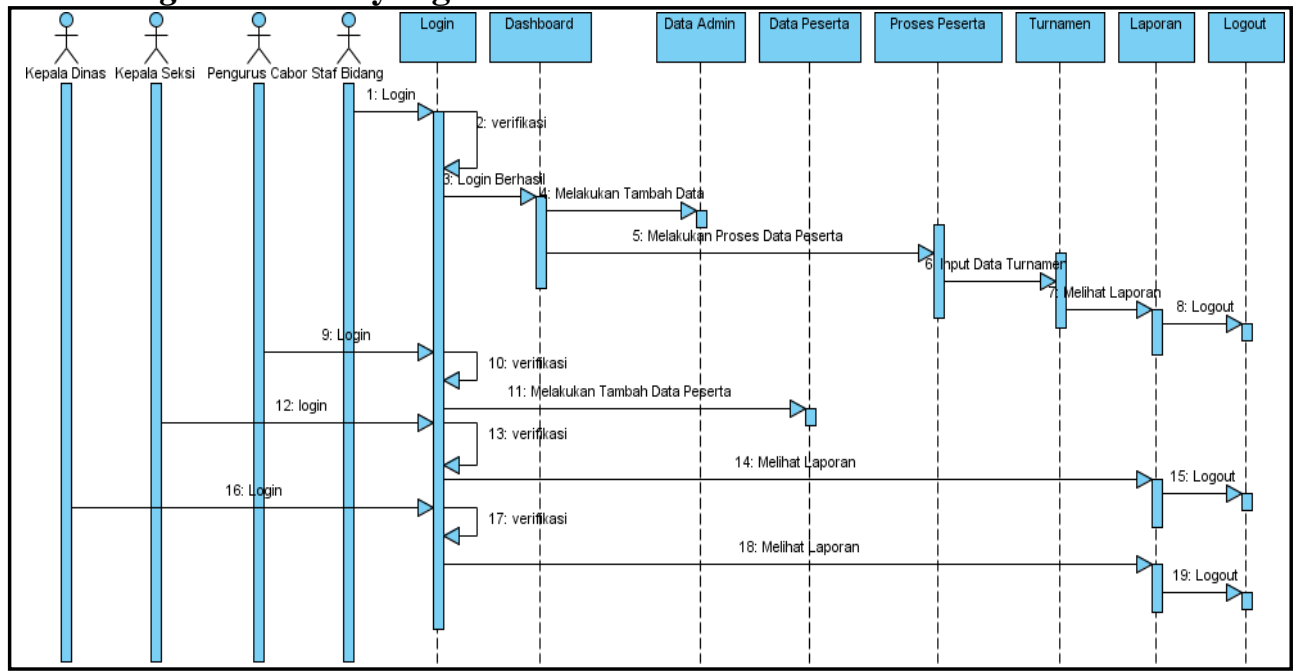

Gambar 3. Sequence Diagram Sistem yang diusulkan

Pada gambar diatas Sequence diagram sistem yang diusulkan, terdapat :

1. Terdapat 8 (delapan) bentuk Lifeline yang mewakili Lifeline Login, Dashboard, Data admin, Data peserta, Proses peserta, Turnamen, laporan dan logout.

2. Terdapat 4 (empat) orang Actor yang melakukan berbagai kegiatan, yaitu Kepala Dinas, Kepala Seksi, Pengurus Cabor dan Staf Bidang.

3. Terdapat 19 (sembilan belas) Message yang mewakili aktivitas dan komunikasi antar objek.

\subsection{Class Diagram Sistem yang diusulkan}

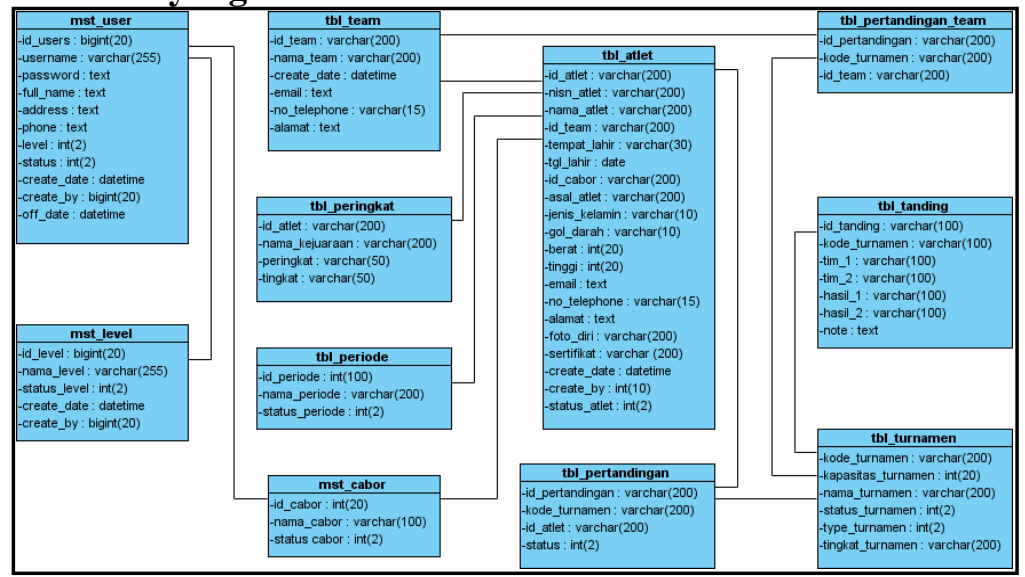

Gambar 4. Class Diagram Sistem yang diusulkan

\subsection{Rancangan Program}

Berikut merupakan tampilan rancangan program dari sistem informasi data kebudayaan yang dibuat pada sistem usulan, yaitu sebagai berikut :

1. Halaman Login 


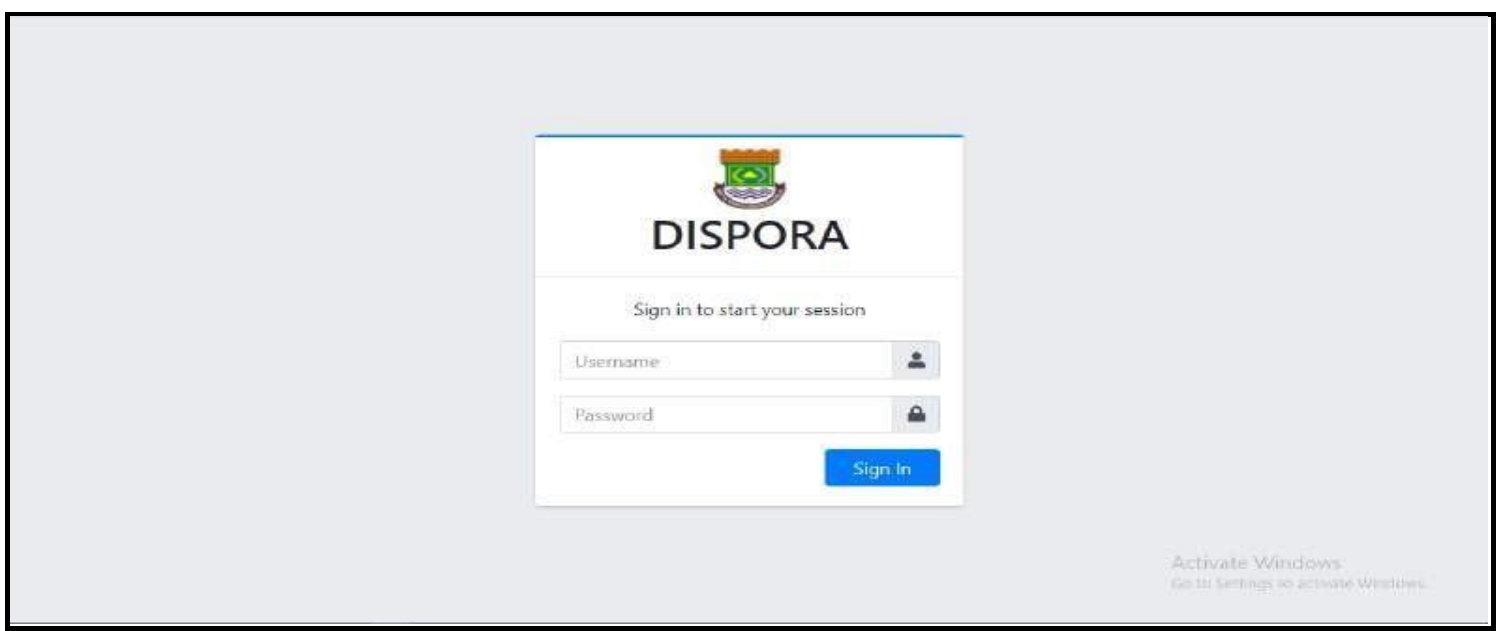

Gambar 5. Halaman Login

2. Halaman Dashboard Admin

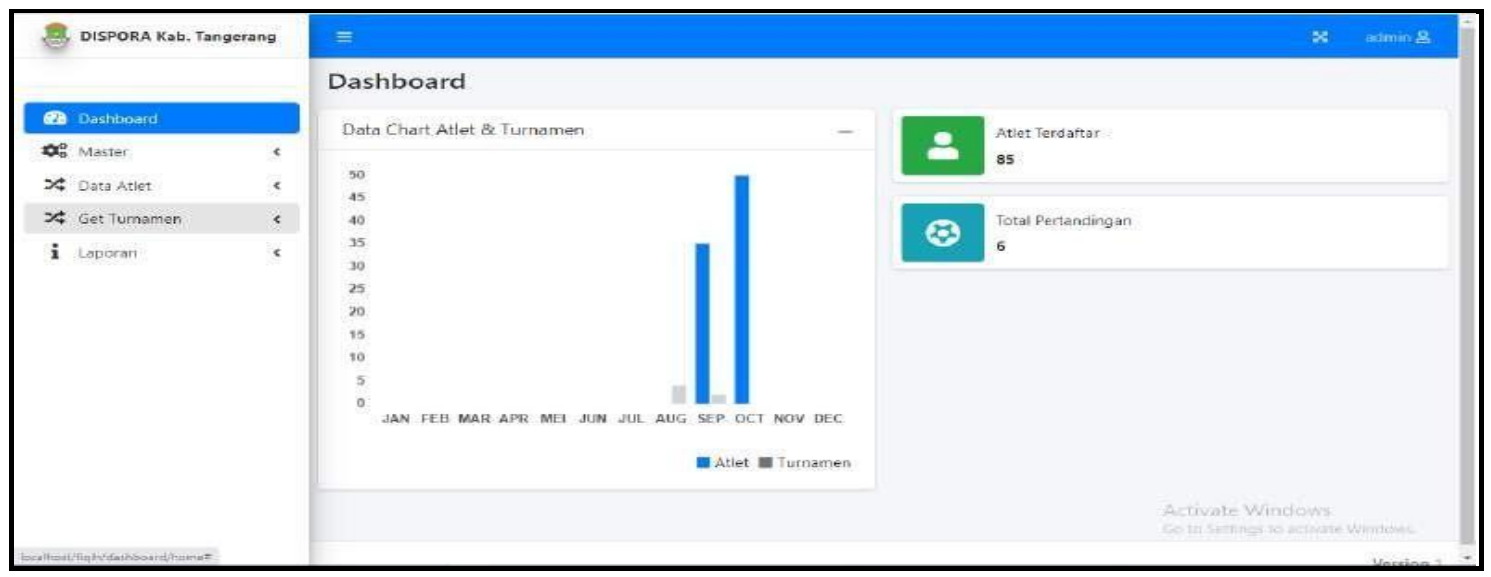

Gambar 6. Halaman Dashboard Admin

Berikut adalah halaman dashboard admin yang dapat melihat total dari keseluruhan data yang telah diinput.

3. Halaman List Data Cabang Olahraga

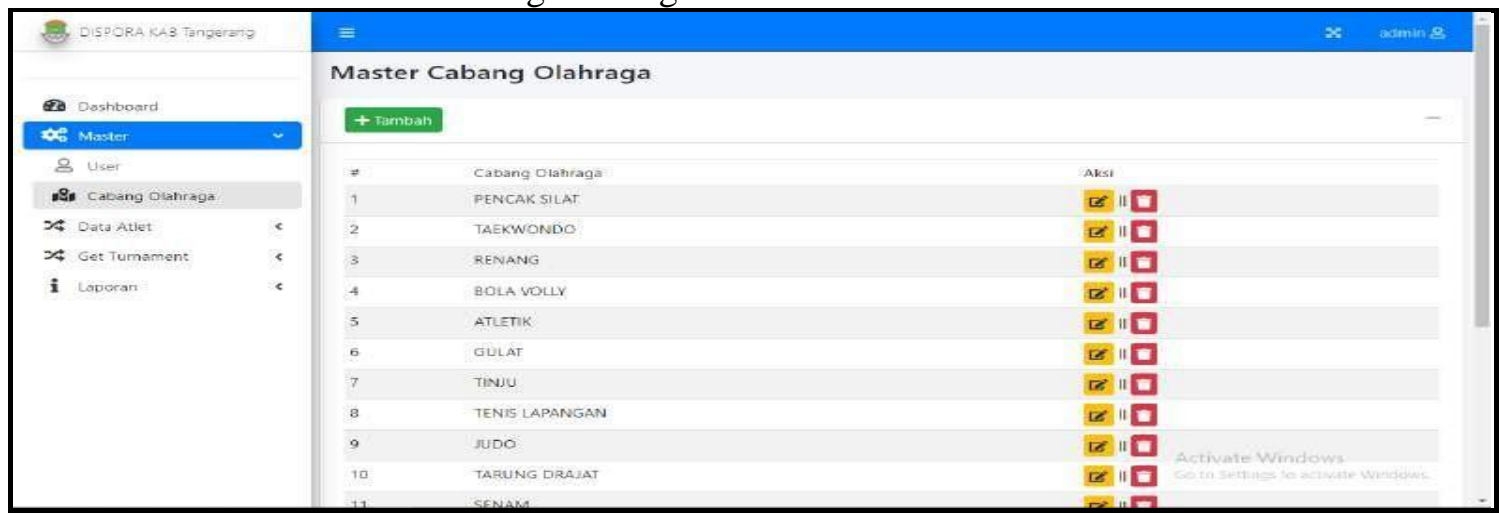

Gambar 7. Halaman List Data Cabang Olahraga

Berikut adalah halaman list data cabang olahraga, yang dapat melihat dari keseluruhan data, dan terdapat beberapa opsi seperti tambah data, edit, maupun hapus data. 
4. Halaman List Data Atlet

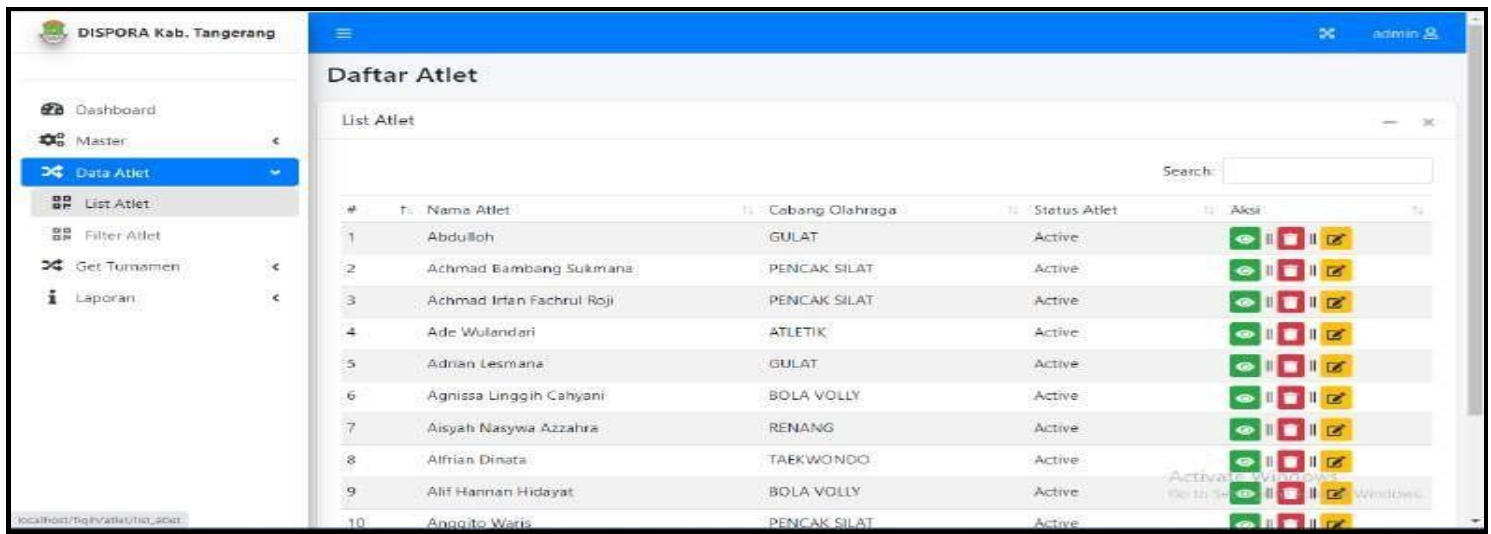

Gambar 8. Halaman List Data Atlet

Berikut adalah halaman list data atlet, yang dapat melihat dari keseluruhan data, dan terdapat beberapa opsi seperti tambah data, detail, edit, maupun hapus data, terdapat juga fitur search untuk mencari data yang diperlukan.

\section{Halaman Tambah Data Atlet Perorangan}

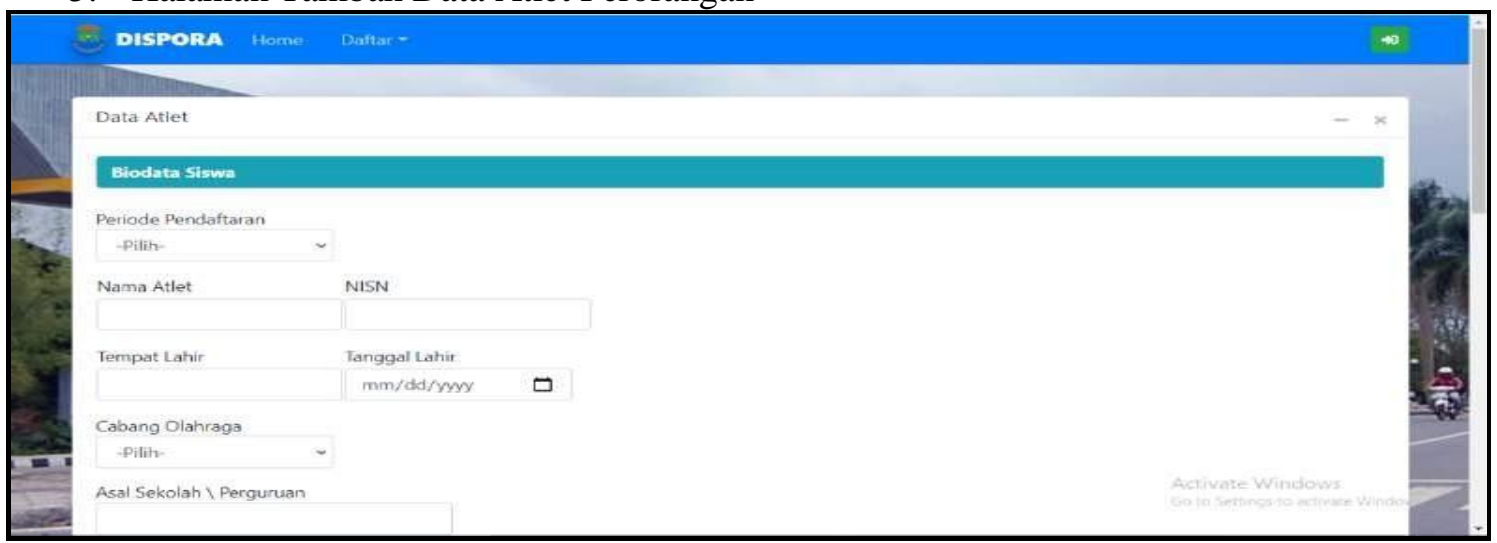

Gambar 9. Halaman Tambah Data Atlet Perorangan

Berikut adalah halaman tambah data atlet perorangan, dan terdapat beberapa field yang harus diisi didalam form tersebut yang selanjutnya akan diinput oleh organisasi.

6. Halaman Tambah Data Atlet Team

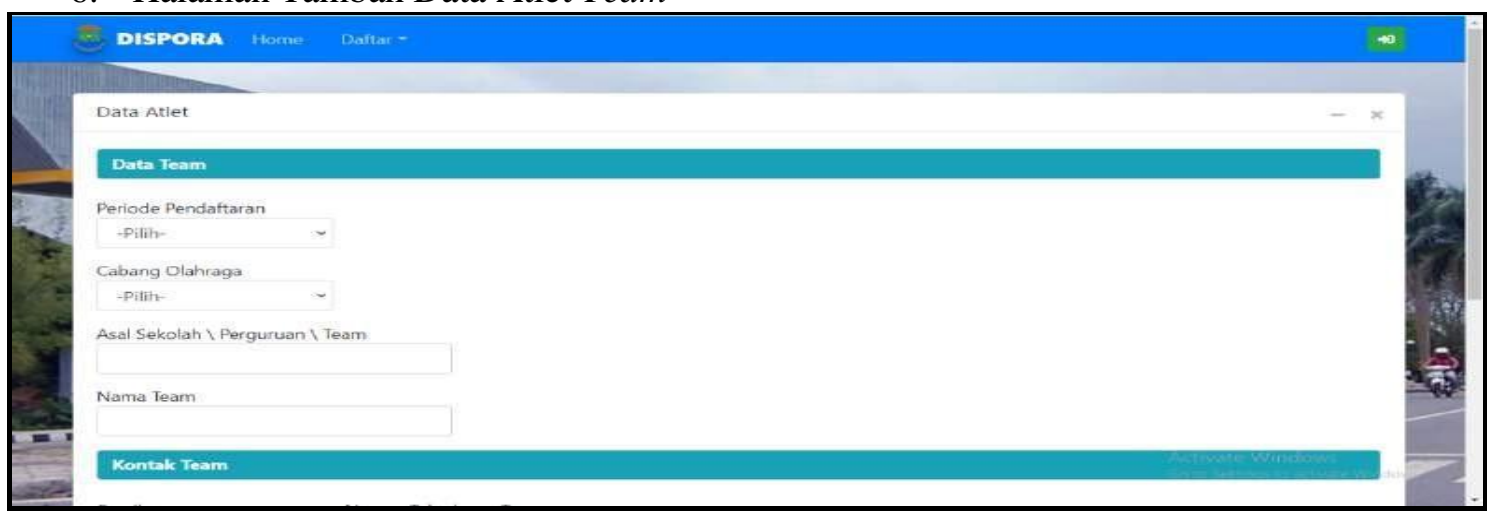

Gambar 10. Halaman Tambah Data Atlet Team 
Berikut adalah halaman tambah data atlet team, dan terdapat beberapa field yang harus diisi didalam form tersebut yang selanjutnya akan diinput oleh organisasi.

7. Tampilan Laporan

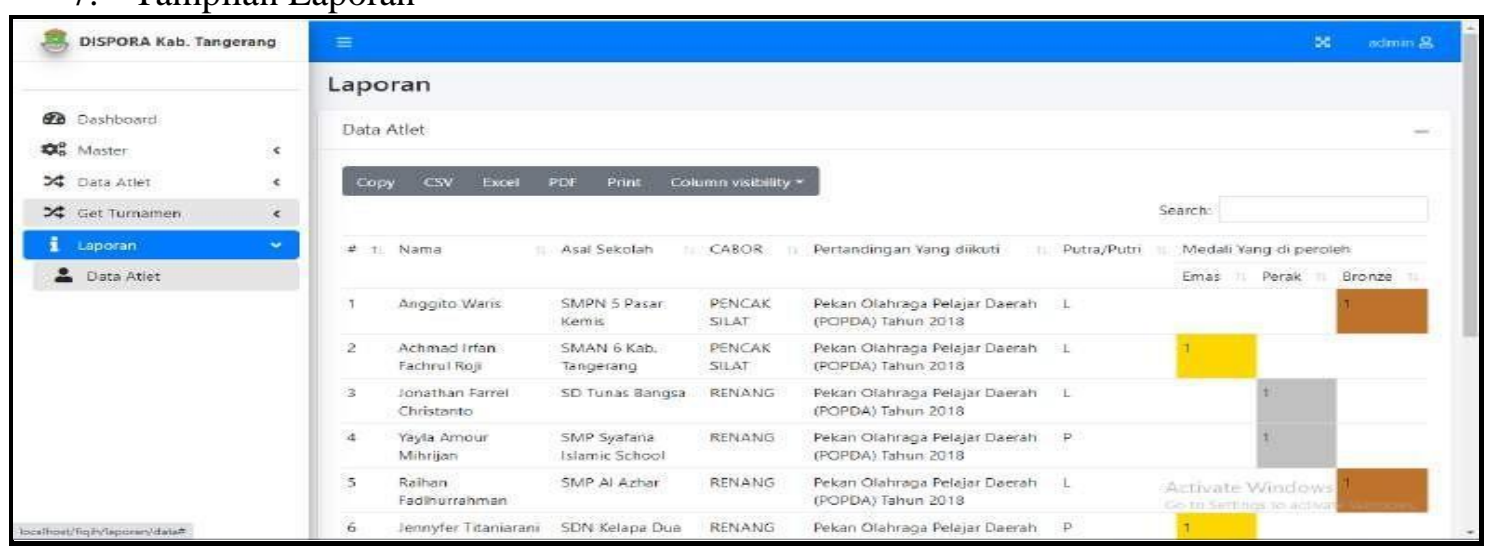

Gambar 11. Tampilan Laporan

Berikut adalah tampilan laporan, bisa mencetak keseluruhan data yang telah diinput dan disimpan dengan format pdf maupun excel.

\section{Halaman Home}

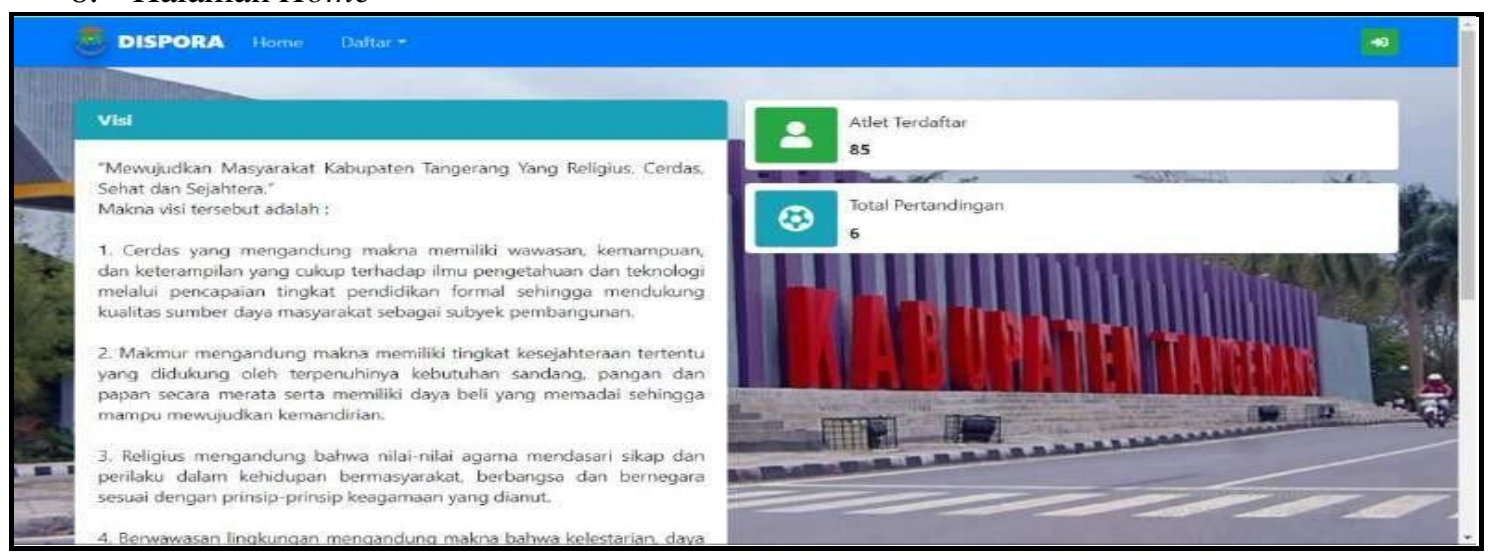

Gambar 12. Halaman Home

Berikut adalah halaman home, halaman pertama saat mengakses website tersebut.

\section{KESIMPULAN}

Kesimpulan dari penelitian yang dibuat meliputi: Sistem yang digunakan untuk mengolah data atlet saat ini masih manual menggunakan kertas-kertas atau dalam software Microsoft Word dan Microsoft Excel sehingga dalam penyimpanan dan pengolahan datanya masih belum terkomputerisasi dengan baik. Maka diperlukannya sebuah sistem untuk mengolah data atlet yang dapat mempermudah dalam proses penginputan dan pengolahan data yang efektif dan dapat terintegrasi dengan baik. 


\section{SARAN}

Disarankan untuk meminimalisir kemungkinan terjadi error maka harus dilakukan pengawasan dan pemeliharaan dari pihak yang bertanggung jawab agar tidak merugikan penggunanya. Disarankan pengguna mencatat jika terdapat kekurangan pada sistem yang diusulkan untuk perbaikan agar sistem dapat lebih sempurna. Disarankan perlu sosialisasi kepada pengguna sehingga dalam menjalankan sistem pengolahan data atlet agar dapat terintegrasi dengan baik.

\section{DAFTAR PUSTAKA}

[1] Abdurahman, Muhdar., dkk. (2018). Sistem Informasi Pengolahan Data Balita Berbasis Website Pada Kantor Upt-Kb Kec. Ternate Selatan. Indonesian Journal on Information System. Volume 3 Nomor 2 | September 2018.

[2] Purwati, Indri. (2019). Regulasi Diri Dan Bentuk Strategi Coping Atlet Wanita Yang Berprofesi Pegawai Negeri Sipil (PNS). Jurnal PSIKOBORNEO, Volume 7, Nomor 1, 2019: 243-254.

[3] Sitorus, J. H. P. (2021). Perancangan Sistem Monitoring Lokasi Kendaraan Menggunakan Gps U-Blox Berbasis Android. Jurnal Bisantara Informatika, 5(1), 10-10.

[4] Karnadi, K., \& Perdana, M. W. (2020). APLIKASI PENGOLAHAN DATA ATLET BERPRESTASI PADA KONI KABUPATEN PALI DENGAN METODE WATERFALL. Jurnal Teknologi Informasi Mura, 12(01), 54-67.

[5] Romdoni, M. Y., \& Ruhiawati, I. Y. (2020). Sistem Informasi Data Atlet Pada KONI Provinsi Banten. Journal of Innovation And Future Technology (IFTECH), 2(1), 81-94.

[6] Kusuma, D. F. B., Marcos, H., \& Yunita, I. R. Rancang Bangun Aplikasi Pengolalaan Data Atlet IKASI Berbasis Website Menggunakan Framework Laravel. 